\title{
INDOMITABLE SISTERHOOD IN KAVITA KANE'S SITA'S SISTER: AN ARCHETYPE OF WOMEN CAMARADERIE
}

\author{
Dr. Hitesh D. Raviya \\ Ms. Parul Malviya
}

\begin{abstract}
Universally bringing its philosophical implications that has been nurturing our minds, the Ramayana has had a huge impact on us and it still does. Often reckoning it for establishing prototypes of brotherhood and male companionship, the epic is laden with many such examples and the eminent amongst them is Ram and his three brothers. But imperceptibly we sense the similar relevance given to sisterhood and women companionship. Kavita Kane, a mythological-fiction writer is known for retelling the stories from the two Indian epics, the Ramayana and the Mahabharata. In her novel Sita's Sister, we stumble upon impregnable sisterhood. The novel is a narration of the Ramayana from perspective of Urmila, in which women-bonding is far and wide visible. From childhood to teenage, and to their adulthood, the four sisters in solidarity lead us on a road that ends in women camaraderie. We encounter many instances in the novel where women stand, speak and support other women. So as we learn principles and ethics from the set models of brotherhood, we can also grasp several virtues from the woman characters. Taking into consideration, how the relationship grows between them as they pass through different stages of their lives, the research paper will analyze how the writer has made their bond competent enough to be set on the pedestal of ideal sisterhood.
\end{abstract}

Keywords: Sisterhood, Women Camaraderie, Prototype, Mythological-fiction, Retelling

Sculpturing and nourishing the society and culture of India for ages, the Ramayana and the Mahabharata are the two epics which are an inseparable part of India's value 
system. And as one of the rising waves today, the art of retelling has brought us the same old tales but with novelty. They favour us to see how society evolves and accepts development. Similarly, modern writers are providing a distinct perspective to these stories and one among them is Kavita Kane. An Indian writer in English who is acknowledged for her fiction writing in mythology, her novels rest on the stories of the Ramayana and the Mahabharata. It is worth emphasizing that the chief characters of the two epics never intrigued her. The feministic approach in her novels is visible through the overlooked woman characters and Kane has given them a voice to narrate their stories. As she is regarded for dealing with unnoticed woman characters, Kane saw these women for more than what they are in the epics and one such novel is Sita's Sister, where Urmila recounts the Ramayana through her viewpoint.

Entwined by the author, one of the major net we can see in the novel is of sisterhood. While we find the ocean of brotherly-love in the Ramayana, there are only few drops of sisterly-love. Through four princesses of Mithila and also through some minor characters like Mandodari and Sumitra, Kane explores the little moments of woman to woman connect. As we look through the epic, we realize the layers of women-bonding hiding under the heavy layers of men-bonding. We fall upon many such examples and to mention a few: the fervent brotherly-love between Ram and his brothers, Ravana and his brothers, Jatayu-Sampati, Nala-Neela and we also get to see strong bond of comradeship like the one between Rama and Hanuman. These are some proclaimed sets of how amity and brotherhood should be, and how can one imbibe to be a selfless and devoted brother or a friend. But we faintly catch the sight of the same prioritization of sisterhood and it gets weakened by the better and acclaimed themes. How often do we encounter such intense female bonds?

It is not that they do not exist, but we have to open our eyes wide and dig in the layers to bring it to attention. It is certainly not like men to men companionship is only praised. We have depiction of both the good and the bad, for example on one hand the relationship between Ram and Laxman is a positive portrayal of brotherhood, on the other hand we see Ravana and Kuber's relationship against it. So we can see the focus 
on both thick and thin of male to male companionship. As far as female companionship is concerned, the positive is not given the due recognition and rather the negative sides are highlighted, for example, Sita and Surpanakha, Kaikeyi and Kaushalya, Manthara and Sita. So do we even find depiction of sisterhood in a way that it is, at once, perceptible? We find the answere to this question in Sita's Sister, where through the point of view of Urmila, we read the Ramayana again, but with novelty. For the fourteen years that Laxamana spend in the exile, Urmila doesn't sleep but rather manages every broken piece of the family together. But in the book we cannot turn a blind eye to the beautifully depicted bond of the four sisters.

The author does not idealize it, instead she shows rough together with the smooth in their relationship. Rather than idolizing them, the author humanizes them by showing their flaws too and what is worth noticing is that, even after their fights and misunderstandings, they never give up on each other but rise strongly after falling short in their bonding. Other than the bond between Sita, Urmila, Mandavi and Shrutikirti, we also discover many instances of women standing for women, speaking and supporting each other, understanding each other and sacrificing for each other. And this delineation is so strong, beautiful and realistic that it keeps us captivated to see their journey, the journey of the sisterhood growing with change in different phases of their lives.

The book is a feminist retelling of the Ramayana from Urmila's frame of mind, and the next major theme that we can observe in the novel the women solidarity. It is compelling enough to be easily perceived by the readers and drives us to ask this question that how often we talk of sisterhood that we learn from the epics as equally as we talk of brotherhood. And the answere can be explored from the mythological-fiction written by Kavita Kane. Through the usual story and characterization we can easily set the images of the virtues we can absorb.

The author of six books, most of the research on Kavita Kane's work is present in the form of research articles, journals, book reviews, and the greater part of which exist as 
comparative research. While we see many book reviews of her novel, in most cases we find research articles analyzing gender discrimination or exploring the character of Urmila but the novel is not yet probed for its delineation of women camaraderie. The theme of sisterhood, women companionship and women-bonding in the novel remains untouched as a primary research theme. Essentially required to be studied, as it is one of the fundamental crux of the novel, exploring the idea of sisterhood in Kavita Kane's Sita's Sister will fill in the gap. And to understand the similar idea in other books of the author, the research paper will also establish a foundation.

The research is done in order to analyze the idea of sisterhood in the novel and whether it is strong enough to be set as an archetype. And if the author has succeeded in making it realistic to be easily taken up by the readers? To examine the structure in which author delineates the women-bonding in the novel, the paper is primarily based on the novel Sita's Sister by Kavita Kane. Exploratory and qualitative in nature, the study will be made in order to understand whether the novel can be regarded as a set example of sisterhood, which will also help to know the aspect of the feminist retelling of the Ramayana from the point of view of Urmila.

A structural part of humankind, mythology is inseparable from the lives of people. It changes with changing religion and culture. However, the basis remains the same that it connects and conjoins people with faith and belief. The stories of gods, godmen, legends, folklores about the formation of universe, creation of man, man's arrival on Earth forms mythology of a culture. Yet mythology does not restrict itself to religion and culture, it is moreover an impression of the principles and ethics that prevailed and still does. In a broad frame, it abounds in moral but does not serve this sole motive. Indian mythology consist of various scriptures; Vedas, Puranas, Samhitas, Aranyakas, Upanishads, Natyashastra, Ramayana, Mahabharata, Bhagavad Geeta, their different versions, and several translations. When the plots and themes are adopted from mythology and blended with the artistic imaginative mind of the author, it creates a mythological fiction. The terms Mythological-Fiction, Mytho-Fiction and Mythic-Fiction can be used synonymously and the credit for their coinage is given to Charles de 


\section{Raviya \& Ms. Parul Malviya/ Page 18-32}

Lint and Terri Windling. The blend can be prepared variously, like narrating the accounts from mythology by changing the point of view, or by maintaining the line of characters while modifying the plot, or by transforming both the story and the characters but gripping on a theme. There are various potential routes while writing a mythological fiction. While dealing in mythological fiction, the author has the liberty to narrate, depict, and retell the stories of a culture's mythology. Yet one has to be cautious in its treatment with creative writing, because mythology is more than just tales. The stories are close to us because they are not just a description about God and Godmen, but through them, an impression about man and his idiocies, his failings and shortcomings, his family and society, his struggle within and the fights with the challenges that life throws at him. It represent the survival of man in a world that inhibits love and hate, selfishness and gratitude, anger and forgiveness, feelings and emotions, war and peace. It is what man puts his beliefs in, and thereby a writer of a mythological fiction might end up in hurting the sentiments of readers.

Together with writing mythological fiction comes the notion of retelling. The art of retelling has brought us the same old tales but with novelty. Reviving the stories from mythology with new ideas, nearly in all our religions and regional languages, there have been several variations of famed threads of the tales, and today significant amount of works are available on its retelling. They favour us to see how society evolves and accepts development. The writing of mythological fiction and retelling is not new, we find it even in the ancient times. From Kalidasa's Abhigyan Shakuntalam to Banabhatta's Kadambari, the genre has always interested the writers and intrigued the readers. In retelling of a story from mythology, the author incorporates the contemporary ideas and issues to make it more engaging for the readers. In the same way modern writers are providing a distinct perspective to these stories. Some of the Indian postcolonial writers like Devdutt Pattnaik, Amish Tripathi, Chitra Banerjee Divakaruni, Anand Neelkantan, Ashwin Sanghi, Ashok Banker, Anuja Chandramouli and Kavita Kane chose mythology as their writing genre and are breaking the barriers and stereotypes with their writing style. 
Sita, Urmila, Mandavi and Shrutikirti, the four adorable princesses of Mithila, with their own individuality yet united by their deep unbreakable sisterly bond. Sita, the eldest of the four and the adopted child of Mithila king and queen, Seerdhwaj Janak and Sunaina, whereas Urmila was born one year later after Sita's adoption. The two cousins, Mandavi and Shrutikirti, were daughters of Kushdhwaja who was the younger brother of Janak. Chandrabhaga, mother of Mandavi and Shrutikirti, lost her life when the two were infants, hence both the sisters were fostered by their uncle and aunt, together with their own daughters. So the four sisters, from their childhood, grow around each other. Being an astute king, Janak was a highly philosophical man and a feminist father. He never hurdled in the way of his daughters and empowered them to pursue their interests by giving them an open sky. They could put forth their ideas, take their own decisions, and question anything that they felt was wrong. Brought up together in a sagacious spirit, the four daughters were the chirping birds in the palace. For the exuberant girls that they were a shade of sistership between them is uncovered in the prologue itself, during the time when they play hide and seek in their grand garden. While the three sisters think they have lost Sita while playing, they start seeking for Sita in the other parts of the palace. Worried for Sita, as well as fearing from the punishment they would get, we see Urmila being ready to take wrath of her father and being adamant about finding Sita, they end up finding her in the marvelous auditorium lifting the hefty Shiva Dhanush.

We get a glimpse of strong heartfelt conversation between the four sisters at the event of Sita's swayamwara. As Mandavi and Kirti(Shrutikirti) are excited for Sita, Urmila is concerned about her sister. The author paints their lively connection in the novel:

The four young girls engaged in such banter all the time. There was no malice in it, not a shred of meanness. They were simply disarmingly frank with each other; brutally blunt sometimes. And why wouldn't they? They were sisters, after all, and there was no need to be nice and good all the time.(8)

They were so perceptible amongst themselves that they could sense any shift in each other's attitude. We also discover Urmila's fondness for Sita throughout the novel. 
When Laxaman kills the demon disguised as Sita, her world collapses and she is even ready to kill him by a dagger. Worth noticing that by this time Urmila was already in love with Laxaman, but the moment she saw him killing Sita, she forgets all the love and affection she had for him and tries to take the revenge upright. Further, their joy is in seventh heaven as they receive the proposal for all four sisters being married to four princess of Ayodhya. They are delighted as the four sisters will be future sister-in-laws. When Sunaina was against the proposal of all four girls getting married in same family, Sita questions her-"How could our staying together harm us? Will marriage lessen our love for each other? No, Ma, it shall strengthen it further, as no one knows us better. We love each other too much for anything or anyone to come between us."(55) Always shielding each other, they stand prepared to safeguard one another's happiness. As happens when Laxaman denies marrying Urmila, and there is an altercation between the two. Manadvi, as a concerned sister says, "Why didn't he want to marry you? After what he said and how he hurt you I swear I was ready to kill him."(71). That is what their nexus was about, to be happy in other's happiness and sad in other's grief. They mutually shared the emotions that they go through. But more than crying for one-another's sorrow, the girls always worked towards finding a solution to their problem. For once, they would stay silent for themselves but never for their sisters. Moreover they apprehend their mother's fear of all four getting married in the same family. They understand that there will be a vast array of duties ahead, but at the end of the day they will be sisters who will always love each other.

In their childhood, even if the four were behind a playful trick, Urmila was the one receiving scolds. When Sunaina observed her getting jealous of Sita, she felt the need of telling her the truth. Urmila, after knowing that Sita was the adopted child, matured then and there. She understood that Sita should never unloved or treated secondary. Urmila became more responsible than a girl of her age in her childhood. After that instance if Sita was always the priority and almost idolized by their parents, there was no resentment among the other girls. 
We do not see them fighting for the attention, or preference over each other. Although they wondered why Sita was almost adored by everyone, there was no trace of jealousy amongst them and on the contrary the girls were happy about the way Sita was praised like a goddess by their parents. Similarly, when Kaikeyi welcomes the four daughter-inlaws in Ayodhya, she does not regard Sita and instead gives all of her titles to Urmila. She calls Urmila as 'daughter of King Janak, Janaki, and Princess of Mithila, Maithili.' Defending her sister, Urmila corrects Kaikeyi by saying that she is none of them. She tells her that all those epithets are of Sita. Even when Ram is told to remarry, Urmila is furious about the idea and again she is prepared to challenge everybody for her sister. There are many such instances in the novel every once in a while, where we can see the sisters speaking for each other. When they see anything unacceptable happening with their siblings, they get furious, worried and angry about it and without a second thought they are up to each other's defence. And then be it with their parents, their husbands, king, queen, rishis or gurus, irrespective of who the person is, they stand for what is right for their sisters.

What is praiseworthy about sisterhood rendered by the author in the novel is that it is not simply idealization of the theme. Although the author has a feministic approach in her novels she does not condemn the brotherly love. While reading a feminist work of writing, there is always a possibility that in order to highlight the women-bonding one might end up brutally criticizing the otherwise actual depiction of brotherhood. But the author manages it remarkably by dealing with both in equality. As she shows the strong bond between the sisters, she does not glorify it. The peaks and troughs, that are part of every human relationship, are found between them too. As a negative character in the epic as well as in the novel, Manthara tries poisoning almost everyone's mind and so she does with the sisters when they arrive in the palace at Ayodhya. She attempts it on all four of them but only Mandavi is being manipulated by her act, whereas Sita, Urmila and Kirti remain unmoved by her tampering. And being affected by deviousness of Manthara, Mandavi indulges in a squabble with her sisters where she questions preference of Ram over Bharat. 
Although speaking in somebody else's tongue, she does not hide her feelings and rather being honest she expresses herself in front of them. She says, "I am not very proud of myself right now. Yes it was my dream to be queen one day but not at the cost of my sisters's happiness. I know you girls don't believe me, but I mean it. I was wrong. I was led to hope, and allowed myself to hope that I was the destined queen as Bharat's wife..."(112). After this affair, the sisters grow apart with misunderstandings between them, and which they could not resolve because of the course of events following in the palace. Their deep and whimsical conversations come to an end, the sisters wouldn't talk the way they used to, and Mandavi starts keeping a distance from the other three. Urmila understood the widening gap and strives to bring everything back at terms with each other as early as possible. She does not have any malign towards Mandavi because she knew whatever Manadavi said was not she but Manthara speaking through her. And so was she actually, as when she returns to Ayodhya and come across the scene of Ram's exile, Mandavi confronts her mistake and says,

Yes, Bharata, remove her from here. She is sweet but oh so deadly! She made me say the most unutterable things to my sisters, whipping a quiet hostility within me towards them. Don't have her any longer! I shudder when I recall how I could be so gullible, so vulnerable- she is a witch who spellbinds and makes us do what she wants with her sweet talk and mind games.(198)

And not just Mandavi but Kirti too realize how Manthara succeeded in breaking them apart. Kirti, always being wiser than her age, reminds the sisters that there is always a little evil residing in each one of us and it only takes a spark of fire to ablaze that evil up. The four women don't hesitate to confess and accept their mistakes. Even if the guilt is higher, their love for each other surpasses it and they would apologize for it. They never fail to admire each other for their virtues and strength, and criticize for vices and faults. And when needed they turn to an escape, a refuge where they can find comfort and peace.

Furthermore what happened with Urmila, happens with Manadavi again. While Laxamana leaves Urmila alone in the palace for Ram, it was his dharma which Urmila 
always knew she will have to face one day. But when she saw the same happening with Mandavi, she could not stop herself from speaking for her sister. She did not counter for herself when Laxmana left her, but she had to do it for Mandavi. She cannot let her sister go through the same pain that she had suffered. The pangs of separation from her husband, the loneliness for fourteen long years, and she will not be able to see her sister swallow her tears. So when Bharat tells everyone that he will lead an ascetic life out of the palace in Nandigram, she argues,

So be it Bharat, like your brothers, Ram and Laxaman, you too shall live a life of an ascetic, free from the bond of love and worldly care. Who cares whatever happen to your wife and your family? She asked, each word mouthed with cold deliberation. Today, in this room, we have talked about all sorts of dharma-of the father and the sons, of the kings and the princes, of the Brahmin and the Kshatriya, even of the wife for husband. But is there no dharma of the husband for his wife? No dharma of the son for his mother? Is it always about the father, sons and brothers?(219)

She questions everybody present in the room about the dharma of a husband towards his wife, of a son towards his mother. Demanding justice for Mandavi, she also speaks for all the women on board. Even after knowing the fact that nothing that she does will change the events, yet she tries with all her might to not let her sisters face the same what she did.

The author not only recounts sisterhood amongst four sisters, but also through other minor characters of the epic. We see Sumitra supporting Kausalya as well as Kaikeyi. She comforts Kausalya as her beloved son Ram leaves the palace, Sumitra says "You've always been proud of your son, so be proud of him now too... Ram is a herobe proud of him, don't grieve for him. He is meant for glory and greatness and a higher salvation. Laxman saw it in him, and decided to follow his footsteps to be with him in his new difficult path. He will see to it that Ram and Sita don't come to any harm."(162) Despite all that she herself was suffering, she stood strong for other women in the palace. In the same direction, when Bharat was spitting his anger out on his mother 
Kaikeyi, Urmila supported her. She saw it in Kaikeyi that whatever she did was out of her love for her son. Urmila says, "Don't Bharat, don't hate your mother so, or punish her so ruthlessly; she did it out of ill-advice, hoping to protect you. She did it out of love."(193) Despite of all the anger and outrage that everybody had for Kaikeyi, it was Urmila and Sumitra who understood her situation and backed her in getting out of it. As Mandavi asks Urmila that why and how is she so respectable towards Kaikeyi, after all that she did to their family, Urmila says "For which she has been punished enough. Her son has disowned her, how much worse can it get for her? By all of us hating her as well? I cannot. It would embitter me. And I feel terrible for her. Call it sympathy and a strong trust that a woman who was so affectionate cannot turn so heartless."(233) Urmila believed in Kaikeyi and hence together with Sumitra she tries her best to lighten up the atmosphere back in the palace. As after the exile and then death of King Dashrath, the family fell apart and the palace was as mournful as grave, the brothers were far apart and it was the ladies of the house who picked up the broken pieces. They eased the tension between the family members and lifted the spirit by cooking together, eating together.

The high spirit of sisterhood is visible when everybody loathed Manthara for her act, but Kaikeyi does not blame Manthara solely for the course of events. We see Kaikeyi scrutinizing herself. She says-

And finally, Manthara. I never imagined that someone whom I loved and trusted from childhood, would give me advice that would bring about my downfall. She was espousing for herself, and not for my cause. And while her poisonous words washed over my head, I found myself actually believing her! And a though struck me- could Manthara have poisoned my mind if there was no fault in me? No greed, no folly, no jealousy, no vanity? The villainy must have always been latent in my heart. (257)

She understood that nobody can corrupt your mind if there is not a single drop of malice reside in you. She confirms to Manthara being one of the reason, but not the only reason behind her misdeeds. Hence, we see that despite of blaming others for the place 
the women in the novel stand, they look within themselves. They do not hold other women accountable for the fate they face.

At a larger canvas, women are usually portrayed women's enemies. Being rivals, or stepping in one another's way. We have been fed with stories of women enmity and so we started believing in the phrase that a woman is a woman's worst enemy. They are rarely depicted backing and supporting each other. There is an urge of talking about sisterhood. As we fight for women's rights, talk of equality, write of feminism, but it should not happen superficially. All the movements, work of writings are fruitful only when they bring slightest change. Therefore, it is important that they help people understand the issues as well as make them understand the need of changes to be made. Therefore, what Sita's sister does to the readers is splendid and significant. It shows a woman comforting, supporting, speaking, fighting, backing and coming to the aid of another woman. The novel shows women companionship in a new light. It tells us that rather than blaming others for placing us in a situation, we should introspect that why could they manipulate us.

The novel has astoundingly depicted sisterhood, through major as well as minor characters, which we cannot overlook. And that is what we can grasp from it, to support women around us in whatever good they are trying to do. To help each other in whatever possible ways we can, by supporting morally and providing strength. The misconception of a woman to woman malice is challenged by the author in the novel. Therefore, we can regard the novel as an exemplar of sisterhood. There is no excessive idealization of the theme, nor does the author blame brotherhood, instead she draws our attention to the question of equality. Her novel Sita's Sister is one such work of fiction which inculcates the lesser emphasized notion of sisterly love. Not making it illusive, as one might think it only exists in books and cannot happen in actual world, the picturization of sisterhood is palatable as the author does not just focus on making it perfect and rather makes it realistic. Hence, in the novel we come across women to women bonding in a reasonable way, where they have fluctuations in their relationships with one another, but they learn from their mistakes. Rather than looking down upon 
each other they stand in solidarity. Despite of the differences that come and go, they have a bond that is unbreakable and strong enough to last till they meet their ends. Therefore magnificently depicting the thread of sisterhood, the novel can be considered as an archetype of women camaraderie. 


\section{Works Cited}

Abraham, Mary Neethu. "Consensual Dominance: The Lethal Combination of Religion and Hegemony." Alochana Chakra Journal, vol. IX, no. VI, May 2020, pp. $1750-$

1753. www.alochanachakra.in/gallery/198-acj-june-2045.pdf.

Abrams, M.H. and Geoffrey Galt Harpham. A Glossary of Literary Terms. Cengage Learning, 2015.

Arekar, Madhavi and Kranti Doibale. "Shurpanaka: The Subversive Journey of a Woman Unheard in Kavita Kane's Lanka's Princess." AJANTA, vol. VIII, no. III, july-sept. 2018, pp. 131-135. dspace.vpmthane.org:8080/jspui/bitstream/123456789/7984/1/28.pdf.

Asha, M. and Dr. R. Nandini. "Retrieval of Female Subjectivity in Indian English Writing: Kavita Kane's Feministic Concern". INFOKARA RESEARCH, vol. 8, no. 11, 2019, pp. 2390-2393. infokara.com/gallery/271-nov-337.pdf.

Batra, Jagdish. "Transforming Culture: The Myth-Fiction Interface in Indian Context." Paper Proceedings of the Fourth International Conference on Language, Literature \& Society 2017. http://dspace.jgu.edu.in:8080/jspui/bitstream/10739/1165/1/Transforming\%20Cult ure.pdf.

Kane, Kavita. Sita's Sister. Rupa Publications, 2014

Kane, Kavita. "Sisterhood In The Ramayana And Why We Need To Talk More Of It." SheThePeople TV, 8 Mar. 2019, www.shethepeople.tv/top-stories/sisterhoodramayana-sita-women-indian-epics.

Thomas, Elizabeth. "Voice of the Voiceless". The Asian Age, 2019. www.asianage.com/age-on-sunday/080919/voice-of-the-voiceless.html.

Vijayan, Vidhya. "Unveiling The Doubly Marginalised: A Feminist Reading Of Kavita Kane's Karna's Wife And Sita's Sister." Literary Endeavour, vol. 10, no. 4, 2018, pp. 136-142. literaryendeavour.org/files/ssy9ikzogu6messgwav2/lssue-201810.pdf. 
Yadav, Puja. "Mythology: A Literary Genre Proliferated Post Millennia." The Criterion: An International Journal in English Vol. 9, No. 3, 2018, pp. 024-033. http://www.thecriterion.com/V9/n3/CT03.pdf.

\author{
Dr. Hitesh D. Raviya \\ Professor and Head \\ Department of English, Faculty of Arts \\ The Maharaja Sayajirao University of Baroda \\ Vadodara, Gujarat \\ Email: hitesh.raviya-eng@msubaroda.ac.in \\ $\&$ \\ Ms. Parul Malviya \\ PhD Scholar \\ The Maharaja Sayajirao University of Baroda, Vadodara \\ Email: parulmalviya73@gmail.com
}

